\title{
MEDIDAS DE GESTÃO AMBIENTAL ADOTADAS EM UM POSTO DE ABASTECIMENTO DE COMBUSTÍVEIS
}

\section{ENVIRONMENTAL MANAGEMENT MEASURES ADOPTED PUT IN A FUEL SUPPLY}

\author{
Daniel Benitti Lorenzett ${ }^{1}$; Marivane Vestena Rossato ${ }^{2}$; Mauricio Neuhaus ${ }^{3}$ \\ ${ }^{1}$ Universidade Federal de Santa Maria - UFSM - Santa Maria - Brasil \\ dlorenzett@gmail.com \\ ${ }^{2}$ Universidade Federal de Santa Maria - UFSM - Santa Maria - Brasil \\ marivavest@gmail.com \\ ${ }^{3}$ Universidade Federal de Santa Maria - UFSM - Santa Maria - Brasil \\ mcneuhaus@gmail.com
}

\begin{abstract}
Resumo
Em função do desequilibrio ambiental mundial as empresas do ramo de postos de combustíveis, que são entidades potencialmente poluidoras, vêm buscando interagir de forma mais harmoniosa com o meio ambiente. Frente a isso, surgiu à necessidade de se identificar a interação dessas entidades com o meio ambiente, quais as medidas de gestão ambiental estão sendo adotadas $e$ quais devem ser adotadas por esse segmento empresarial. Nesse sentido, este trabalho buscou verificar as medidas de gestão ambiental que devem ser adotadas de acordo com a legislação ambiental existente. Para o desenvolvimento do estudo, foi realizado um estudo de caso com o emprego da técnica de observação aliada à técnica da entrevista estruturada, junto a um posto de combustiveis, localizado na cidade de Santa Maria - RS. Os resultados revelaram que a entidade interage com o meio ambiente quando utiliza a água como insumo nas atividades desenvolvidas $e$ pela geração de resíduos como: óleo queimado, filtros usados, lodo tóxico, vapores de combustíveis, embalagens de lubrificantes e efluentes líquidos. Constatou-se, ainda, que estes resíduos e efluentes são todos tratados pela adoção de medidas de gestão ambiental, sugerindo, portanto, que a empresa estudada contribui efetivamente para a preservação ambiental.
\end{abstract}

Palavras-chave: gestão ambiental; legislação ambiental; postos de combustíveis.

\section{Introdução}

O mundo só recentemente despertou para a importância das questões relacionadas à proteção do meio ambiente. Contudo, em função dos imensos impactos já causados a natureza, e dos efeitos atualmente sentidos em função desses impactos, essa preocupação surge na esfera global de forma latente. Assim, a gestão ambiental integra o rol de prioridades debatidas no âmbito das ciências ambientais, ocupando uma posição de destaque nesses debates (LORENZETT; ROSSATO, 2010; CAVALCANTI, 2010). Perante a situação exposta as empresas com maior potencial poluidor passaram a desenvolver e implantar instrumentos de gestão ambiental corporativa, visando 
melhorias nos fluxos de informações internas e externas, e consequentemente reduzindo o risco de acidentes ambientais (BARATA; KLIGERMAN; MINAYO-GOMEZ, 2008).

Nesse sentido, o setor de distribuição de combustíveis, que é considerado como atividade potencialmente poluidora para o meio ambiente, uma vez que pode poluir as águas, o solo e o ar, vem investindo em proteção ambiental e buscando adequar-se as legislações ambientais existente, para assegurar que essa atividade não agrida o meio ambiente (LORENZETT; ROSSATO, 2010). Nesse âmbito, as administrações públicas estão estabelecendo normas e procedimentos mais seguros e adequados para tais empresas, que põem em risco a integridade do meio ambiente. Segundo a Federação Nacional do Comércio de Combustíveis e Lubrificantes FECOMBUSTÍVEIS (2011), a preocupação com a questão ambiental tornou-se indispensável na vida do empreendedor do ramo de comercio de combustíveis, pois eles precisam estar atentos não somente as determinações da Resolução do Conselho Nacional do Maio Ambiente (CONAMA) $n^{\circ}$ 273/2000, mas também as legislações estaduais específicas, de forma a proteger o meio ambiente e evitar incorrer em multas e outras punições.

No Brasil, a principal base legal que regulamenta a atividade de posto de abastecimento de combustível consiste basicamente da Resolução CONAMA nº. 237/97, e da Resolução CONAMA $n^{\circ}$. 273/2000, a primeira Resolução cita a atividade de posto de abastecimento de combustível como sujeita ao licenciamento ambiental e a segunda padroniza os procedimentos e o licenciamento dessas entidades, bem como de todas as demais atividades que possuem armazenagem de combustíveis. Além dessas duas Resoluções existem também outras legislações, como as normas técnicas expedidas pela Associação Brasileira de Normas Técnicas (ABNT), e as legislações estaduais específicas de cada Estado. Explicitou-se, dessa forma, a necessidade de normatização e fiscalização dessas atividades, bem como a autuação daqueles que não cumprem a legislação ambiental específica.

Tomando por base essa contextualização, evidenciou-se a necessidade dos postos de combustíveis se adequarem às normas estabelecidas pelos órgãos competentes, para se resguardar o equilíbrio do meio ambiente. Nesse contexto, este trabalho pretende estudar as medidas de gestão ambiental que estão sendo adotadas e as que devem ser adotadas pelo segmento de abastecimento de combustíveis. O presente trabalho surgiu diante à necessidade de obtenção de informações referentes à adoção de medidas de gestão ambiental no segmento de abastecimento de combustíveis. Nesse enfoque, pretendeu-se chamar atenção para a problemática ambiental, quanto ao posicionamento do empresário da atividade de comércio de combustíveis perante a legislação ambiental, e das medidas adotadas para adequar-se a essa legislação. 
Assim, este estudo realizou especificamente a caracterização do funcionamento e identificou os procedimentos inerentes à atividade de posto de abastecimento de combustível; identificou de que forma ocorre à interação da entidade com o meio ambiente; e levantou as medidas de gestão ambiental que estão sendo adotadas e as que devem ser adotadas para atender a legislação vigente.

\section{Referencial teórico}

\subsection{Postos de combustíveis}

No Brasil, o transporte rodoviário predomina, e o petróleo além de ser a maior fonte de energia fóssil é também o mais importante e indispensável fonte dos combustíveis utilizados nesse tipo de transporte. Nesse sentido, é de vital importância para a economia do país a existência da cadeia de postos de abastecimento de combustíveis, estrategicamente, disposta em todo território nacional. Os empreendedores que desejarem atuar nesse ramo devem sujeitar-se as normas estabelecidas pela Agência Nacional do Petróleo, Gás Natural e Bicombustível (ANP), pois esta é a agência regulamentadora das atividades relacionadas à indústria de petróleo, gás natural e de bicombustíveis do Brasil. Ainda, devem sujeitar-se também as determinações do Conselho Nacional do Meio Ambiente (CONAMA) que é o responsável pela legislação ambiental pertinente a atividade, as Normas Técnicas (NBR) expedidas pela Associação Brasileira de Normas Técnicas (ABNT), e as legislações específicas de cada Estado (LORENZETT; ROSSATO, 2010; LORENZETT et al., 2011).

Segundo Santos (2005), os postos de combustíveis possuem basicamente as seguintes instalações: a unidade de abastecimento de veículos (bomba de gasolina), os tanques de combustíveis (geralmente enterrados), os pontos de descarga de combustíveis, onde os carrostanques fazem o reabastecimento dos postos revendedores de combustíveis, o tanque para recolhimento e guarda de óleo lubrificante usado (geralmente enterrados), as tubulações enterradas que comunicam o ponto de descarga com o reservatório e este com as bombas de abastecimento, as edificações para escritório e arquivo morto, a loja de conveniência, o centro de lubrificação e o centro de lavagem, a unidade de filtragem de diesel, o sistema de drenagens oleosas e fluviais e os equipamentos de proteção e controle de derrames e vazamentos de combustíveis, bem como de segurança quanto a incêndios e explosões.

Pode-se elencar como atividades desenvolvidas pelos postos de combustíveis o recebimento e armazenamento de combustíveis, o abastecimento dos veículos, operação do sistema de drenagem oleosa, troca de óleo e filtros, lavagens de veículos, e operação da loja de conveniência (SANTOS, 2005, LORENZETT; ROSSATO, 2010). Segundo Lorenzett e Rossato (2010), essas atividades são 
consideradas potencialmente poluidoras, uma vez que manuseiam produtos derivados de petróleo e podem causar danos ao meio ambiente, caso ocorram acidentes ou até mesmo por descuido.

A seguir são apresentados, no Quadro 1, os possíveis impactos ambientais que podem transcorrer em decorrência das operações desse segmento empresarial, correspondente às atividades relacionadas ao manuseio de combustíveis. Como demonstrado no Quadro 1, as atividades relacionadas ao manuseio de combustíveis são o recebimento desses produtos, sua armazenagem, o abastecimento dos veículos, o sistema de drenagem das pistas e o tratamento dos efluentes líquidos na caixa separadora de água e óleo. Estas atividades estão sujeitas a uma série de incidentes, que vão desde a simples emissão de gases até incêndios e explosões. Observa-se ainda no Quadro 1, que as causas desses incidentes consistem, basicamente, na falta de manutenção dos respiros dos tanques e por descuidos, que possibilitem a presença de fontes de ignição na área dos postos, impactando diretamente a qualidade do ar.

Quadro 1 - Impactos Ambientais por atividade desenvolvida / Manuseio de Combustíveis

\begin{tabular}{|c|c|c|c|}
\hline ATIVIDADES & INCIDENTE & CAUSAS & IMPACTOS \\
\hline \multirow{2}{*}{$\begin{array}{c}\text { Recebimento de } \\
\text { Produto: Gasolina / } \\
\text { Diesel / Álcool }\end{array}$} & $\begin{array}{c}\text { Emissão de Compostos } \\
\text { Orgânicos Voláteis } \\
\text { (COV) }\end{array}$ & $\begin{array}{c}\text { Respiro dos Tanques } \\
\text { Enterrados }\end{array}$ & Qualidade do Ar \\
\hline & $\begin{array}{l}\text { Derrame de Produto / } \\
\text { Incêndio e explosão }\end{array}$ & $\begin{array}{c}\text { Extravasamento e } \\
\text { Presença de Fonte de } \\
\text { Ignição }\end{array}$ & $\begin{array}{c}\text { Solo / Águas Superficiais e } \\
\text { Subterrâneas / Qualidade do } \\
\text { Ar }\end{array}$ \\
\hline \multirow{2}{*}{$\begin{array}{l}\text { Armazenagem de } \\
\text { Produto }\end{array}$} & Emissão de COV & $\begin{array}{l}\text { Respiro dos Tanques } \\
\text { Enterrados }\end{array}$ & Qualidade do Ar \\
\hline & Vazamento de Produto & $\begin{array}{l}\text { Furo de Tanques e } \\
\text { Tubulações }\end{array}$ & Solo / Águas Subterrâneas \\
\hline \multirow{4}{*}{$\begin{array}{l}\text { Abastecimento de } \\
\text { Veículo }\end{array}$} & Emissão de COV & $\begin{array}{l}\text { Respiro dos Tanques } \\
\text { Enterrados }\end{array}$ & Qualidade do Ar \\
\hline & Derrame de Produto & $\begin{array}{l}\text { Filtro de Diesel / Bombas } \\
\text { / Extravasamento }\end{array}$ & \multirow{2}{*}{$\begin{array}{c}\text { Solo / Águas Superficiais / } \\
\text { Águas Subterrâneas }\end{array}$} \\
\hline & $\begin{array}{l}\text { Lançamentos de } \\
\text { Resíduos }\end{array}$ & $\begin{array}{c}\text { Disposição Inadequada: } \\
\text { Estopas / Mantas } \\
\text { Absorventes } \\
\end{array}$ & \\
\hline & Incêndio / Explosão & $\begin{array}{l}\text { Presença de Fonte de } \\
\text { Ignição }\end{array}$ & Pessoas \\
\hline \multirow{2}{*}{$\begin{array}{c}\text { Sistema de Drenagem } \\
\text { da Pista / Tratamento } \\
\text { via Caixa Separadora } \\
\text { de Água e Óleo (CSAO) }\end{array}$} & $\begin{array}{l}\text { Efluentes Líquidos: } \\
\text { Águas Oleosas }\end{array}$ & $\begin{array}{l}\text { Extravasamento / Falta de } \\
\text { Manutenção / Operação } \\
\text { Inadequada }\end{array}$ & \multirow{2}{*}{$\begin{array}{c}\text { Solo / Águas Superficiais / } \\
\text { Águas Subterrâneas }\end{array}$} \\
\hline & $\begin{array}{l}\text { Lançamentos de } \\
\text { Resíduos }\end{array}$ & $\begin{array}{c}\text { Disposição Inadequada: } \\
\text { Óleo Usado / Areia e } \\
\text { Borras da CSAO } \\
\end{array}$ & \\
\hline
\end{tabular}

Fonte: adaptado de Santos (2005)

Com relação aos serviços agregados oferecidos pelos postos de combustíveis, como pode ser observar no Quadro 2, são elencadas as atividades de troca de óleo e lubrificantes, a lavagem de veículos, os escritórios e as lojas de conveniência, que impactam as águas e o solo através do 
consumo irracional da água, da disposição inadequada dos resíduos e da falta de tratamento e reciclagem.

Quadro 2 - Impactos Ambientais por atividade desenvolvida / Serviços Agregados

\begin{tabular}{|c|c|c|c|}
\hline ATIVIDADES & INCIDENTE & CAUSAS & IMPACTOS \\
\hline \multirow{2}{*}{$\begin{array}{l}\text { Troca de Óleo } \\
\text { Lubrificante }\end{array}$} & Derrame de Produto & Operações Inadequadas & \multirow{2}{*}{$\begin{array}{l}\text { Solo / Águas Superficiais / } \\
\text { Águas Subterrâneas }\end{array}$} \\
\hline & $\begin{array}{l}\text { Lançamentos de } \\
\text { Resíduos }\end{array}$ & $\begin{array}{c}\text { Disposição Inadequada } \\
\text { de embalagens e resíduos }\end{array}$ & \\
\hline \multirow{4}{*}{ Lavagem de Veículos } & Alto Consumo de Água & $\begin{array}{l}\text { Ausência de Processo de } \\
\text { Reciclagem }\end{array}$ & $\begin{array}{l}\text { Degradação da Bacia Hídrica } \\
\text { Subterrânea }\end{array}$ \\
\hline & $\begin{array}{c}\text { Efluentes Líquidos: } \\
\text { Águas Oleosas com } \\
\text { detergentes } \\
\end{array}$ & Falta de Tratamento & \multirow{2}{*}{$\begin{array}{l}\text { Solo / Águas Superficiais / } \\
\text { Águas Subterrâneas }\end{array}$} \\
\hline & $\begin{array}{l}\text { Lançamentos de } \\
\text { Resíduos }\end{array}$ & $\begin{array}{c}\text { Disposição Inadequada: } \\
\text { Estopas / Embalagens de } \\
\text { Detergentes }\end{array}$ & \\
\hline & Ruído & $\begin{array}{l}\text { Falta de manutenção / } \\
\text { isolamento }\end{array}$ & Pessoas da Vizinhança \\
\hline \multirow[t]{2}{*}{$\begin{array}{c}\text { Loja de Conveniência / } \\
\text { Escritórios }\end{array}$} & $\begin{array}{l}\text { Lançamentos de } \\
\text { Resíduos }\end{array}$ & $\begin{array}{c}\text { Disposição Inadequada: } \\
\text { Lixo doméstico e de } \\
\text { escritório }\end{array}$ & \multirow{2}{*}{$\begin{array}{l}\text { Solo / Águas Superficiais / } \\
\text { Águas Subterrâneas }\end{array}$} \\
\hline & $\begin{array}{l}\text { Efluentes Líquidos: } \\
\text { Esgoto }\end{array}$ & $\begin{array}{l}\text { Disposição Inadequada: } \\
\text { Sem tratamento }\end{array}$ & \\
\hline
\end{tabular}

Fonte: Adaptado de Santos (2005)

Os impactos ambientais causados pelo desenvolvimento das atividades de posto de combustível podem ser controlados ou até mesmo evitados, desde que, se invista na adoção de medidas de gestão ambiental (LORENZETT; ROSSATO, 2010). Para tanto, é necessário conhecer melhor os conceitos e práticas de gestão ambiental.

\subsection{Gestão e práticas ambientais}

O interesse pela qualidade ambiental foi reforçado pela globalização que desenvolveu um mercado mundial sem fronteiras, provocando o acirramento da competição empresarial e a utilização em larga escala de critérios ambientais, além de inovações tecnológicas como elementos de diferenciação no mercado. O que pode ser mencionado, nesse sentido é que a redução ou eliminação da degradação ambiental consiste em um grande desafio, onde operar em harmonia com o meio ambiente constitui-se numa questão fundamental, pressionando as organizações (FREY; WITTMANN, 2006).

A gestão ambiental tem como princípio alinhar as atividades humanas a fim de que estas gerem o menor impacto possível sobre o meio ambiente, desde a escolha das melhores técnicas de processamento das atividades até o cumprimento da legislação para o destino correto dos recursos. A gestão ambiental pode ser considerada como um sistema de planejamento, responsabilidades, práticas e procedimentos para desenvolver e implementar políticas ambientais que influenciam 
diretamente no controle dos problemas ambientais que a empresa tem ou poderá ter no futuro (TINOCO; KRAEMER, 2004; RONNENBERG; GRAHAM; MAHMOODI, 2011). Assim, a gestão ambiental busca, por meio de planejamento organizacional, encontrar novas alternativas que tornem as empresas mais competitivas e com menor incidência na geração de problemas ambientais (FREY; WITTMANN, 2006).

A gestão ambiental para ser eficiente precisa ser bem planejada. Assim, um plano de gestão, para ser efetivo deve ser preventivo ao invés de corretivo, visando o futuro, para proteger efetivamente os recursos remanescentes e restaurar ou reabilitar as unidades ambientais danificadas. O plano de gestão ambiental deverá promover o desenvolvimento urbano e o ordenamento dos serviços, abrangendo todos os setores sociais, além de ações voltadas a proteção do patrimônio natural (CAVALCANTI, 2010).

Outra prática de gestão ambiental comumente adotada consiste na implantação da série ISO 14000 passa pela elaboração de Sistemas de Gestão Ambiental (SGA), previstos na NBR ISO 14001. A ISO 14001, assim como as demais normas internacionais de gestão ambiental, tem por objetivo prover as organizações com um sistema de gestão ambiental passível de integração com qualquer outro requisito de gestão, de forma a auxiliá-las a alcançar seus objetivos ambientais e econômicos. A principal finalidade da ISO 14001 é equilibrar questões como poluição, proteção e preservação ambiental com as necessidades socioeconômicas das organizações (FREY; WITTMANN, 2006; BARATA; KLIGERMAN; MINAYO-GOMEZ, 2007; MASSOUD; DAILY; BISHOP, 2011). Os programas e práticas ambientais associados a um SGA, apresentados na ISO 14001, são considerados fatores importantes na redução do impacto das empresas no ambiente natural (MASSOUD; DAILY; BISHOP, 2011), ajudando as entidades a alcançar um melhor desempenho ambiental através da utilização de práticas padronizadas, documentação, comunicação e aprendizagem organizacional (RONNENBERG; GRAHAM; MAHMOODI, 2011).

Segundo Massoud, Daily e Bishop (2011), a construção da gestão ambiental envolve elementos como: formação ambiental, capacitação ambiental, desempenho ambiental percebido, e trabalho em equipe, pois sem esses elementos não é possivel efetivar a gestão ambiental, principalmente sem a formação ambiental que cria a consciência nos funcionários sobre as exigências de controle ambiental, aumentando a flexibilidade e promovendo uma atitude pró-ativa em relação ao ambiente.

Diante os problemas ambientais e frente à rapidez com que a degradação ambiental vem crescendo, a educação ambiental tem se tornado uma questão humanitária cada vez mais importante e necessária em todas as esferas da sociedade (BRAGA et al., 2002; JACOBI, 2003), podendo ser elencada como uma prática de gestão ambiental, pois na sociedade os grupos com maior 
conhecimento ambiental apresentam melhores atitudes ambientais (ESCRIVAO; NAGANO; ESCRIVAO FILHO, 2011). Assim, a educação ambiental pode ser entendida como uma prática educativa de ensino multidisciplinar formal ou informal, para transformar e construir novas posturas, hábitos e condutas, formando e conscientizando os cidadãos de suas responsabilidades perante o meio ambiente (ESCRIVAO; NAGANO; ESCRIVAO FILHO, 2011).

É importante, ainda para este trabalho o conceito de logística reversa (LR), pois os postos de combustíveis, ainda que inconscientemente, fazem uso dessa prática de gestão ambiental para dar o destino final correto aos resíduos gerados nas atividades. O conceito de logística reversa esta relacionado ao planejamento, operacionalização e controle do fluxo de retorno dos bens de pósvenda e de pós-consumo para o ciclo produtivo, através dos canais de distribuição reversos, agregando-lhes valore econômico, ecológico e competitivo, melhorando a imagem corporativa (LEITE, 2006; ADLMAIER; SELLITTO, 2007; LAGARINHOS; TENORIO, 2008).

\subsection{Legislação ambiental aplicada aos postos de combustíveis}

A atividade de comércio varejista de combustíveis, os chamados postos de gasolina, está submetida à legislação ambiental desde 1981 pela Lei Federal nº 6.938, que foi regulamentada pelo Decreto Federal n. ${ }^{\circ}$ 99.274/90. Esse ramo também foi considerado como atividade sujeita ao licenciamento ambiental pela Resolução CONAMA no 237 de 1997. A última e mais importante norma que regulamenta a atividade foi a Resolução CONAMA n $273 / 00$. Essa resolução veio para padronizar as atividades que possuem reservatórios e armazenamento de combustíveis, quanto às medidas de gestão ambiental e quanto ao licenciamento dessa atividade (LORENZETT; ROSSATO, 2010).

No Rio Grande do Sul, o órgão responsável pelo licenciamento ambiental e pela fiscalização das determinações estabelecidas nas Resoluções do CONAMA, desde 1997, é a Fundação Estadual de Proteção Ambiental Henrique Luiz Roessler, RS (FEPAM). A Resolução CONAMA nº 273/00, determina em seu art. $1^{\circ}$ que todas as atividades referentes ao setor de armazenamento e distribuição de combustíveis, deverão ser realizadas em conformidade com as normas técnicas expedidas pela ABNT ou pelo órgão ambiental competente (LORENZETT; ROSSATO, 2010; LORENZETT et al., 2011). De acordo com a Resolução do CONAMA no 273/00, em seu Art. $4^{\circ}$, será exigido do posto de combustível as seguintes licenças ambientais, para poder operar:

\footnotetext{
- Licença Prévia (LP): concedida na fase preliminar do planejamento do empreendimento aprovando sua localização e concepção, atestando a viabilidade ambiental e estabelecendo os requisitos básicos e condicionantes a serem atendidos nas próximas fases de sua implementação;
} 
- Licença de Instalação (LI): autoriza a instalação do empreendimento com as especificações constantes dos planos, programas e projetos aprovados, incluindo medidas de controle ambiental e demais condicionantes da qual constituem motivo determinante;

- Licença de Operação (LO): autoriza a operação da atividade, após a verificação do efetivo cumprimento do que consta das licenças anteriores, com as medidas de controle ambiental e condicionantes determinados para a operação (CONAMA, 2000, n/p).

Segundo o Art. $6^{\circ}$, §1 e 2, da Resolução do CONAMA nº 273/00, todos os empreendimentos deverão, no prazo de seis meses, a contar da data de publicação desta Resolução, cadastrar-se junto ao órgão ambiental competente, tendo o mesmo prazo, ao término do cadastramento, para elaborar suas agendas e critérios de licenciamento ambiental. De acordo com o Art. $8^{\circ}$, dessa mesma Resolução, os proprietários, arrendatários ou responsáveis pelo estabelecimento, em caso de impactos ambientais e consequentes passivos ambientais, responderão solidariamente pelos prejuízos causados, sejam eles ao meio ambiente ou as pessoas. O Art. $9^{\circ}$, da Resolução do CONAMA $n^{\circ} 273 / 00$, estabelece que os certificados de conformidade tenham sua exigibilidade a partir de $1^{\circ}$ de janeiro de 2003.

No Art. 12, da mesma resolução, ficam estabelecidas as penalidades em caso de descumprimento do disposto na Resolução, no caso, o previsto nas Leis $n^{\circ} 6.938$, de 31 de agosto de 1981; $\mathrm{n}^{\circ} 9.605$, de 12 de fevereiro de 1998 e no Decreto $\mathrm{n}^{\circ} 3.179$, de 21 de setembro de 1999, revogado pelo decreto $\mathrm{n}^{\mathrm{o}} 6.514$, de 22 de julho de 2008, onde são definidas como penalidades multa simples ou diária, à perda ou restrição de incentivos e benefícios físcais concedidos pelo poder público, à perda ou suspensão de participação em linhas de financiamento em estabelecimentos oficiais de crédito, à suspensão parcial ou total da atividade, a prestação de serviços à comunidade, a interdição temporária de direitos e o recolhimento domiciliar.

Segundo a FEPAM são condições para o desenvolvimento da atividade de posto de abastecimento de combustível e para a concessão da Licença Operacional que o estabelecimento atenda os requisitos estabelecidos nas NBR 13784 da ABNT, que normatiza o sistema de detecção de vazamentos; na NBR 12235 da ABNT, que normatiza a forma de armazenamento dos resíduos gerados na atividade e NBR 10004 da ABNT, que dispõe sobre as embalagens de produtos consideradas como resíduos perigosos e sua obrigatoriedade de devolução ao fornecedor destes produtos. Com o conhecimento do que determinam tais Normas, o empreendedor terá as condições mínimas para assegurar o cumprimento dos processos de gestão ambiental que devem ser realizados pelos postos de abastecimento de combustíveis (LORENZETT et al., 2011).

\section{Metodologia da pesquisa}

Quanto à abordagem da pesquisa, o trabalho foi considerado qualitativo. Segundo Richardson (2008) o método qualitativo consiste na tentativa de se entender a natureza do problema 
de estudo, através da observação e descrição, tendo por objeto situações complexas ou estritamente particulares, sem utilizar-se de procedimentos estatísticos para análise de tal problema, imprimindo certo teor de subjetivismo a pesquisa.

Em relação aos objetivos, esta pesquisa foi considerada descritiva e exploratória, pois observou as situações e relações que ocorreram com o objeto estudado, sem que para isso, houvesse interação do pesquisador com o objeto alvo de estudo, constituindo-se num trabalho inicial, que fundamentará outro tipo de pesquisa, uma vez que o assunto estudado é recente e pouco explorado. Para Andrade (1999), a pesquisa descritiva será aquela onde os fenômenos do mundo físico e humano são estudados, analisados e interpretados, mas não manipulados pelo pesquisador, e a pesquisa exploratória será aquela que proporcionar maiores informações sobre um assunto ainda pouco estudado.

Quanto aos procedimentos técnicos, a pesquisa fez uso dos seguintes procedimentos: estudo de caso; pesquisa documental; técnica da observação; e técnica da entrevista estruturada. O estudo de caso foi realizado no posto de combustíveis, Investimento em Proteção Ambiental tem seu Retorno Ltda, localizado na cidade de Santa Maria (RS), onde foram observados as atividades realizadas no estabelecimento e principalmente foram identificadas as medidas de gestão ambiental adotadas na entidade.

Segundo Marconi e Lakatos (2005), a pesquisa documental é uma forma de coleta de dados restrita a documentos, que são as chamadas fontes primárias, como jornais, imagens, leis e gravações. Este procedimento foi realizado através da análise de documentos (alvarás, licenças, certificados ambientais e outros) disponibilizados pela administração do estabelecimento estudado, para verificação da legislação pertinente a atividade de posto de abastecimento de combustível e para verificação das medidas de gestão ambiental que devem ser adotadas pelo estabelecimento segundo determinações dessa legislação.

O procedimento da observação, para Martins (2006), ao mesmo tempo em que permite a coleta de dados das situações, envolve a percepção sensorial do observador. Nessa etapa da pesquisa foram observadas durante o período de um dia as instalações do posto de combustível, sem interferir nas rotinas operacionais desenvolvidas no estabelecimento.

Segundo definições de Marconi e Lakatos (2005), a entrevista estruturada é aquela onde o entrevistador segue um roteiro com perguntas predeterminadas. Nesse sentido, tendo por base a revisão de literatura sobre gestão ambiental e sobre postos de combustíveis, bem como conversas informais junto a representantes da FEPAM, foi elaborado um roteiro com questões abertas que contemplarem dimensões como: questões relacionadas à gestão e aspectos ambientais; operacionalização das atividades; conhecimento de leis e normas que regulamentam a atividade; 
implantação de licenças ambientais; e treinamento de pessoal para resposta a incidentes ambientais. A entrevista foi realizada com os gestores do estabelecimento, pois eles eram detentores de habilidades técnicas voltadas ao desenvolvimento das atividades de postos de combustíveis em conformidade com as determinações legais da atividade, envolvendo as questões ambientais.

As informações coletadas no estudo de caso foram analisadas qualitativamente, tendo por base os conhecimentos obtidos durante o estudo, através das várias técnicas de pesquisa utilizadas, principalmente aqueles obtidos por meio da revisão de literatura. Para apresentação final dos resultados foram utilizados, esquemas, quadros e figuras, para possibilitar melhor entendimento, além de tornar a leitura mais atrativa.

\section{Resultados e discussões}

\subsection{As atividades desenvolvidas no posto de combustíveis estudado}

Através do uso da técnica de observação, foi constatado que no estabelecimento adotado para o desenvolvimento do estudo, são realizadas as seguintes atividades:

a) Atividade de armazenamento de combustível: para desenvolvimento dessa atividade a empresa possui três tanques subterrâneos localizados ao lado do posto. Estes tanques possuem capacidade para 30 mil litros de combustível cada, perfazendo um total de 90 mil litros de combustível armazenados na entidade;

b) Atividade de abastecimento de veículos: essa atividade é realizada pelos frentistas e ocorre na pista de abastecimento através das bombas de abastecimento, consistindo basicamente no comércio de combustíveis para o consumidor final;

c) Atividade de lavagem de veículos: A lavagem de veículos é realizada com água da chuva e com o auxilio de flanelas e esponjas. Essa atividade ocorre em local apropriado e possui uma boa clientela, apresentando um fluxo constante de entrada de valores;

d) Atividade de troca de óleo, filtros e de lubrificação: as atividades são desenvolvidas numa rampa construída para proporcionar maior segurança na operacionalização da atividade, onde a condução do óleo queimado é realizada através de tubulações, sendo, encaminhado dessa rampa de troca até o tanque reservatório de óleo queimado de forma canalizada, evitando assim o contato com o meio externo, de acordo com a legislação vigente;

e) Atividade de loja de conveniência: Nessa atividade é realizada somente a revenda de lanches, pois a produção dos alimentos é terceirizada de forma a proporcionar maior segurança e satisfação aos clientes, uma vez que o local não é apropriado à produção de alimentos. 


\subsection{Interação do posto de combustível com o meio ambiente}

A interação com o meio ambiente, como demonstrado no Quadro 3, ocorre em função do consumo de recursos naturais e dos resíduos gerados pela atividade, principalmente quanto ao destino dado a esses resíduos decorrentes das atividades operacionais realizadas no estabelecimento.

Quadro 3 - Interação da atividade com o meio ambiente

\begin{tabular}{|c|c|c|c|}
\hline $\begin{array}{c}\text { ATIVIDADE } \\
\text { DESENVOLVIDA }\end{array}$ & $\begin{array}{c}\text { RECURSOS } \\
\text { NATURAIS } \\
\text { CONSUMIDOS } \\
\end{array}$ & $\begin{array}{l}\text { RESÍDUOS / } \\
\text { EFLUENTES } \\
\text { GERADOS } \\
\end{array}$ & $\begin{array}{l}\text { DESTINO DOS } \\
\text { RESÍDUOS / } \\
\text { EFLUENTES } \\
\end{array}$ \\
\hline $\begin{array}{c}\text { Armazenamento de } \\
\text { combustível }\end{array}$ & Não consome & Vapores tóxicos & Lançado diretamente no ar \\
\hline \multirow{2}{*}{ Abastecimento de veículos } & \multirow[t]{2}{*}{$\begin{array}{c}\text { Água da chuva para } \\
\text { limpeza }\end{array}$} & Efluentes líquidos & $\begin{array}{l}\text { Tratados e eliminados no } \\
\text { esgoto comum }\end{array}$ \\
\hline & & $\begin{array}{l}\text { Flanelas utilizadas no } \\
\text { abastecimento }\end{array}$ & $\begin{array}{c}\text { São recolhidas por empresa } \\
\text { especializada }\end{array}$ \\
\hline \multirow[b]{2}{*}{ Lavagem de veículos } & \multirow[t]{2}{*}{$\begin{array}{l}\text { Água da chuva como } \\
\text { matéria-prima }\end{array}$} & Efluentes líquidos & $\begin{array}{c}\text { Tratados e eliminados no } \\
\text { esgoto comum }\end{array}$ \\
\hline & & $\begin{array}{c}\text { Flanelas, estopas e } \\
\text { esponjas utilizadas nas } \\
\text { lavagens } \\
\end{array}$ & $\begin{array}{c}\text { São recolhidas por empresa } \\
\text { especializada }\end{array}$ \\
\hline \multirow[b]{2}{*}{$\begin{array}{l}\text { Troca de óleo, filtro e } \\
\text { lubrificação }\end{array}$} & \multirow[t]{2}{*}{$\begin{array}{c}\text { Água da chuva para } \\
\text { limpeza }\end{array}$} & Efluentes líquidos & $\begin{array}{c}\text { Tratados e eliminados no } \\
\text { esgoto comum }\end{array}$ \\
\hline & & $\begin{array}{l}\text { Óleo queimado, filtros } \\
\text { usados, embalagens de } \\
\text { lubrificantes, flanelas e } \\
\text { estopas utilizadas nas } \\
\text { atividades }\end{array}$ & $\begin{array}{c}\text { São recolhidos por empresa } \\
\text { especializada e enviados } \\
\text { para aterros sanitários ou } \\
\text { reciclados }\end{array}$ \\
\hline Loja de conveniência & $\begin{array}{l}\text { Água da chuva para } \\
\text { limpeza }\end{array}$ & Efluentes líquidos & $\begin{array}{c}\text { Tratados e eliminados no } \\
\text { esgoto comum }\end{array}$ \\
\hline $\begin{array}{c}\text { Tratamento dos efluentes } \\
\text { líquidos }\end{array}$ & Não consome & Lodo tóxico & $\begin{array}{l}\text { É recolhido por empresa } \\
\text { especializada }\end{array}$ \\
\hline
\end{tabular}

Fonte: Lorenzett e Rossato (2010)

Conforme demonstrado no Quadro 3, as atividades geram resíduos sólidos e líquidos. Tais resíduos por serem potencialmente perigosos ao meio ambiente, e devem ser eliminados de forma segura. Assim, a entidade prima por tratar os efluentes líquidos, e terceirizar a disposição final dos resíduos sólidos para empresas especializadas nesse serviço.

A interação desastrosa, como pode ser vista no esquema da Figura 1, está associada a aspectos ambientais que evidenciam os elementos que surgem das atividades e dos processos desenvolvidos pelo posto de combustível, que se relacionam com o meio ambiente.

As atividades desenvolvidas pelo posto de combustível mantêm relações diretas e intensas com o meio ambiente, através do contato com os compartimentos solo, água e ar. Esse contato é evidenciado através dos aspectos ambientais apresentados na Figura 1. Tais aspectos são os agentes causadores dos mais variados tipos de impactos ambientais, como: a contaminação do ar, das águas 
superficiais e subterrâneas, das águas dos rios locais, das águas da bacia hidrográfica da região e a contaminação do solo.

Figura 1 - Organograma das principais formas desastrosas de interação com o meio ambiente

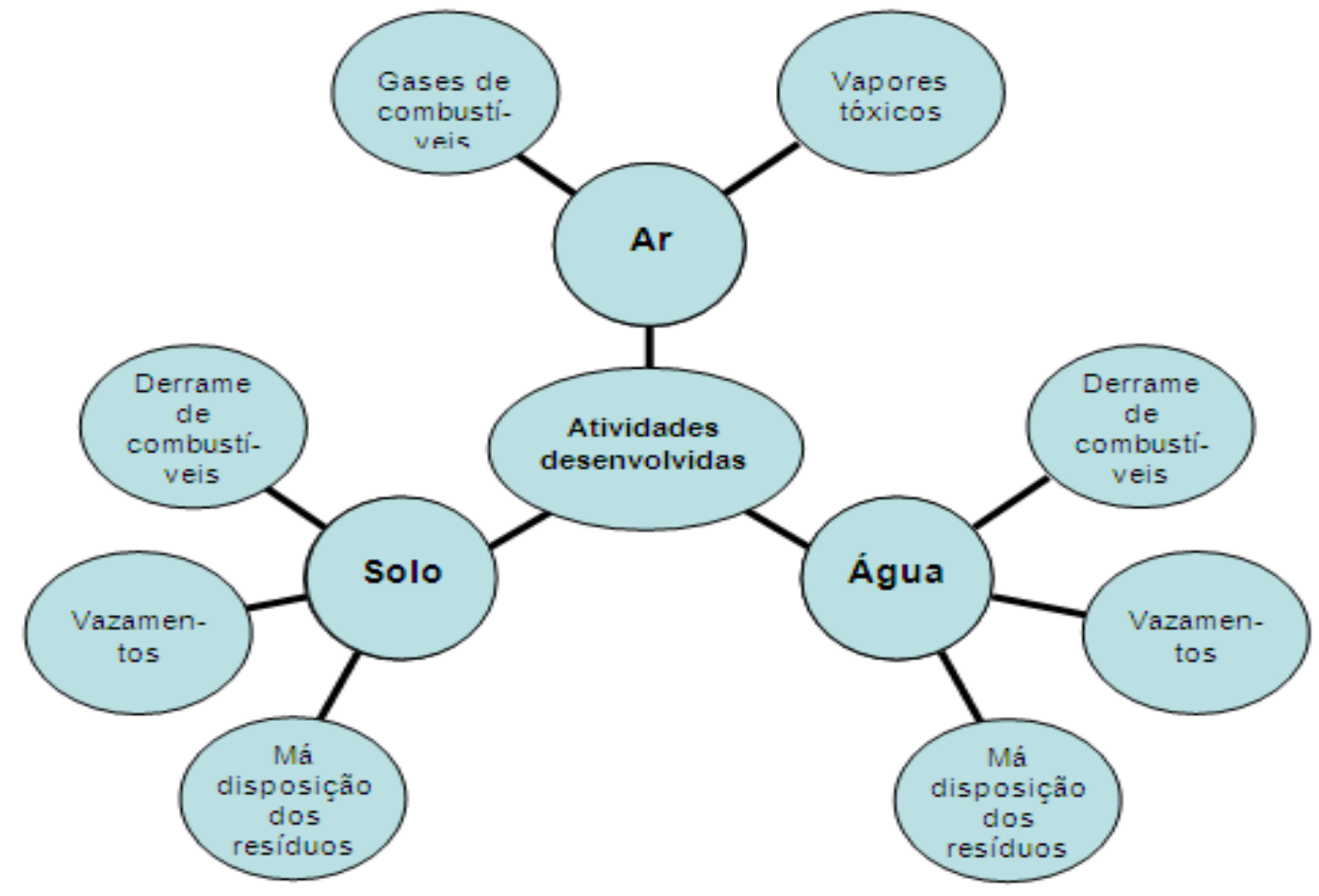

Fonte: Estudo de caso (2010)

Esses impactos relacionam-se direta e indiretamente com a redução da diversidade da fauna e da flora, podendo, comprometer, da mesma forma, a saúde humana, especialmente dos colaboradores que desenvolvem as atividades no posto de abastecimento de combustível. As principais vias do contato desastroso com o meio ambiente consistem:

a) No derrame de combustível no solo;

b) No contato da água da chuva que cai sobre o posto com o solo, com as águas superficiais e subterrâneas;

c) No contato da água da lavagem da pista de abastecimento e da área dos tanques com o solo, com as águas superficiais e subterrâneas;

d) No vazamento de tanques subterrâneos de armazenamento de combustível;

e) No desprendimento de gases dos combustíveis lançados na atmosfera;

f) No acondicionamento inadequado dos resíduos e embalagens de lubrificantes.

Quanto aos aspectos, aqui não somente em relação aos efluentes / resíduos, mas também quanto ao consumo de recursos naturais, nos quais a empresa interage com o meio ambiente, podem 
ser citados os seguintes: a captação e utilização da água da chuva, o tratamento e devolução ao meio ambiente da água utilizada, o armazenamento de combustível, o monitoramento do combustível armazenado, o abastecimento de veículos, os cuidados durante o abastecimento e a manutenção de uma área verde no perímetro do posto.

A posição da empresa frente a estes aspectos consiste em utilizar dos recursos naturais sempre de forma responsável, procurando não agredir o meio ambiente, reduzindo os custos da atividade e auxiliando na manutenção do meio de forma que ele possa continuar a fornecer a matéria prima para o desenvolvimento das atividades continuamente. Onde através do monitoramento pode-se identificar possíveis agressões ao meio ambiente de forma tempestiva e corrigi-las imediatamente.

\subsection{Levantamento das medidas de gestão ambiental}

Através da técnica da observação e da entrevista estruturada foi observado que o posto estudado esta adotando todas as medidas exigidas pelos órgãos fiscalizadores no âmbito ambiental, necessárias para que se possa exercer a atividade de posto de combustível, verificou-se também que a adoção dessas medidas data do período da licença de implantação (LI), como condição para a obtenção da licença de operação (LO).

A pesquisa junto ao estabelecimento revendedor de combustíveis possibilitou o levantamento das medidas exigidas pelo órgão ambiental para a concessão e renovação da licença de operação, como pode ser observado no Quadro 4. 
Quadro 4 - Medidas de gestão exigidas dos postos de combustíveis pelo órgão físcalizador

\section{MEDIDAS DE GESTÃO EXIGIDAS PELO ÓRGÃO FISCALIZADOR}

Coletar semestralmente amostras dos poços de monitoramento para verificação da qualidade da água subterrânea para controle e detecção de vazamentos do sistema de abastecimento subterrâneo de combustíveis, devendo ser apresentado laudo anual ao órgão fiscalizador das análises realizadas;

O óleo queimado, somente pode ser coletado por empresa licenciada pelo órgão ambiental estadual, com comprovação dessa alienação via nota fiscal; as águas utilizadas, caso devolvidas à natureza deverão passar por processo de decantação em caixa separadora de água e óleo;

A comercialização de lubrificantes fica condicionada à compra de fornecedores que realizam a coleta das embalagens pós-consumo, ou seja, a logística reversa dos materiais pós-consumo;

O piso da pista de abastecimento deve ser impermeável com drenagem conectada a caixa separadora, não sendo permitido abastecimento fora dele;

O abastecimento dos tanques subterrâneos somente poderá ser realizado por veículo licenciado para fontes móveis de poluição no órgão ambiental;

Fica proibida a utilização de tanques subterrâneos remanufaturados;

A área de lavagem dos veículos deve ser drenada e conectada a caixa separadora, sendo seu piso impermeável;

A limpeza e manutenção da caixa separadora devem ser realizadas conforme especificações do órgão fisscalizador;

Quanto às emissões atmosféricas deve ser realizada manutenção nos dispositivos de controle de vapores dos tanques subterrâneos conforme especificações do fabricante e apresentado laudo anual dessas manutenções;

Deve ser apresentada, anualmente, comprovação da destinação correta, dos resíduos gerados, como lodo da caixa separadora, embalagens de lubrificantes, óleo queimado, flanelas e estopas;

Devem ser mantidos ao menos dois funcionários treinados nas atividades de controle ambiental, prevenção e combate a incêndios e acidentes, com comprovação anual;

Deve manter uma área de preservação de $577,50 \mathrm{~m}^{2}$.

Fonte: Pesquisa (2010)

As medidas de gestão ambiental adotadas, como podem ser observadas na Figura 2, são basicamente medidas de controle e prevenção ambiental, e em geral estão intimamente relacionadas às atividades desenvolvidas no posto de combustível estudado. 
Figura 2 - Organograma de gestão ambiental desenvolvida por atividade

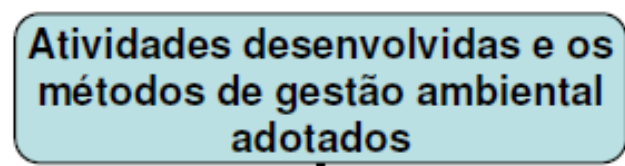

adotados

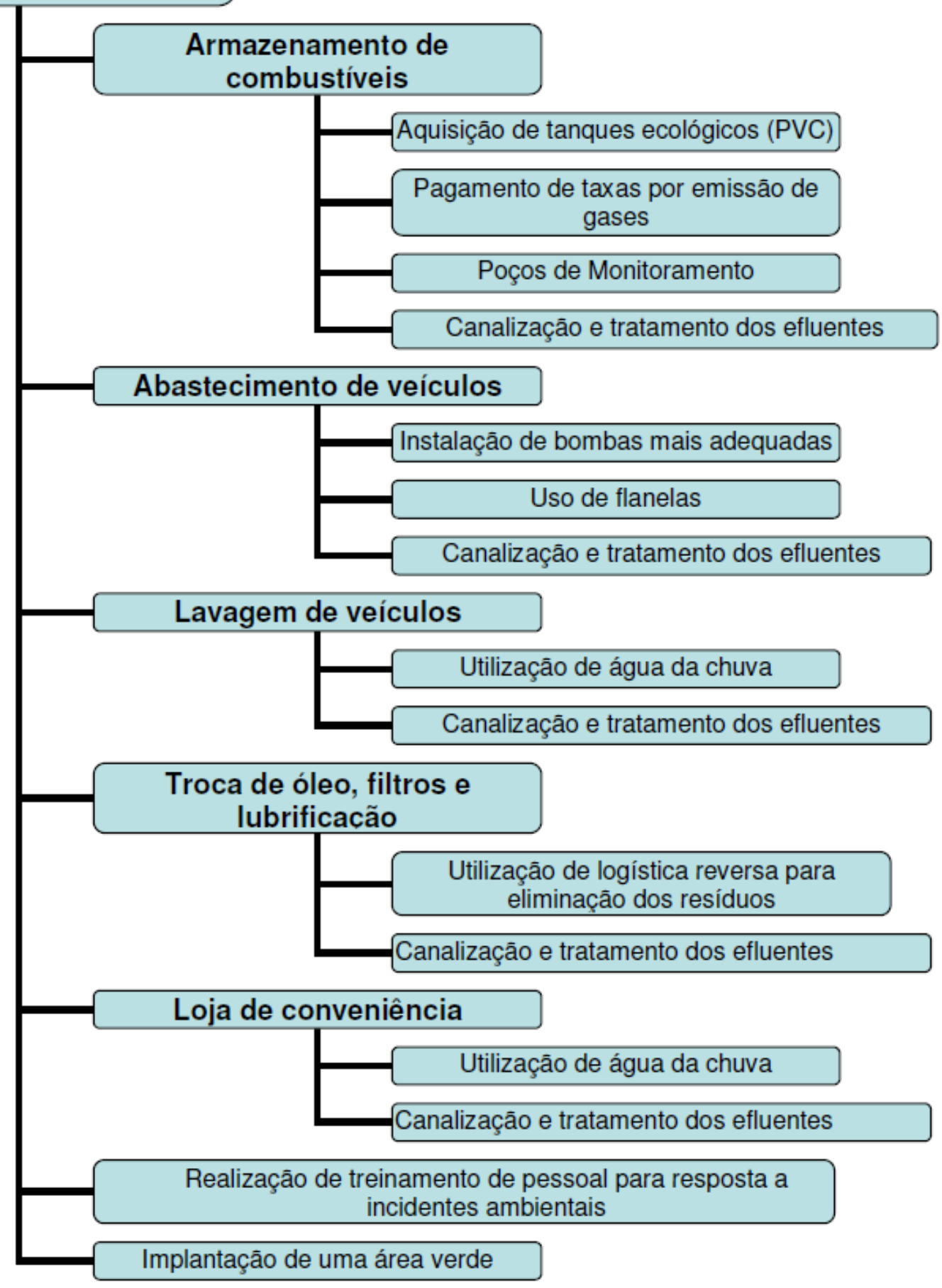

Fonte: Estudo de caso (2010)

Como medida de controle ambiental, o posto de combustível estudado adotou para o armazenamento de combustível, tanques ecológicos anticorrosivos, de forma a evitar possíveis vazamentos. Além dessa medida, o posto mantém dois poços de monitoramento na área dos tanques 
subterrâneos, donde são retiradas amostras das águas subterrâneas semestralmente para verificar seu grau de pureza, de forma a assegurar que essas águas não serão contaminadas.

Como complemento, é adotado o controle dos volumes de combustíveis que entram e que saem, através do Livro de Movimentação de Combustível (LMC). Esse livro não foi adotado meramente por exigência legal, mas sim como ferramenta para monitoramento de vazamentos de combustíveis, baseado na premissa de que todo combustível que entra deve sair, caso o volume de saída de combustível seja inferior ao volume de entrada, pode haver vazamentos, que podem ser identificados em tempo hábil para impedir maiores danos.

Caso ocorram acidentes ambientais, o posto possui pessoal treinado e equipamentos para imediato controle da situação, mas é imprescindível que a FEPAM seja imediatamente comunicada bem como as refinarias fornecedoras (co-responsáveis) para que se possa mensurar e controlar plenamente os danos.

Outra medida de gestão ambiental muito importante adotada pelo posto consiste no aproveitamento da água da chuva e no tratamento dos efluentes líquidos, onde são retirados da água os resíduos químicos antes de sua devolução para a natureza, através da caixa separadora de água e óleo, que é formada por uma grande caixa subterrânea, subdividida em varias caixas menores, onde a água fica decantando para remoção dos resíduos de combustíveis. Assim, após a remoção do lodo tóxico da água se obtêm uma água turva e meio barrenta, não podendo ser reutilizada na atividade, portanto seu destino consiste no lançamento junto ao esgoto comum, ao passo que os resíduos químicos provenientes da separação são estocados para posterior coleta por empresa especializada. O fluxograma da Figura 3 representa o esquema do ciclo da água no posto de abastecimento de combustível, compreendendo desde o processo de captação da água da chuva, sua utilização, seu tratamento e devolução a natureza.

Quanto o que determina a Resolução nº 273/2000 do CONAMA, foram realizados todos os estudos pertinentes à localização das instalações antes do início de sua construção, os estudos referentes à adoção de tecnologias ecologicamente corretas, para as instalações do estabelecimento, e aqueles previamente à entrada em operação, bem como os testes e ensaiados nos equipamentos e sistemas para a comprovação da inexistência de falhas ou vazamentos, de forma a possibilitar a avaliação de sua conformidade com o Sistema Brasileiro de Certificação. 
Figura 3 - Diagrama do ciclo da água no posto de abastecimento de combustível

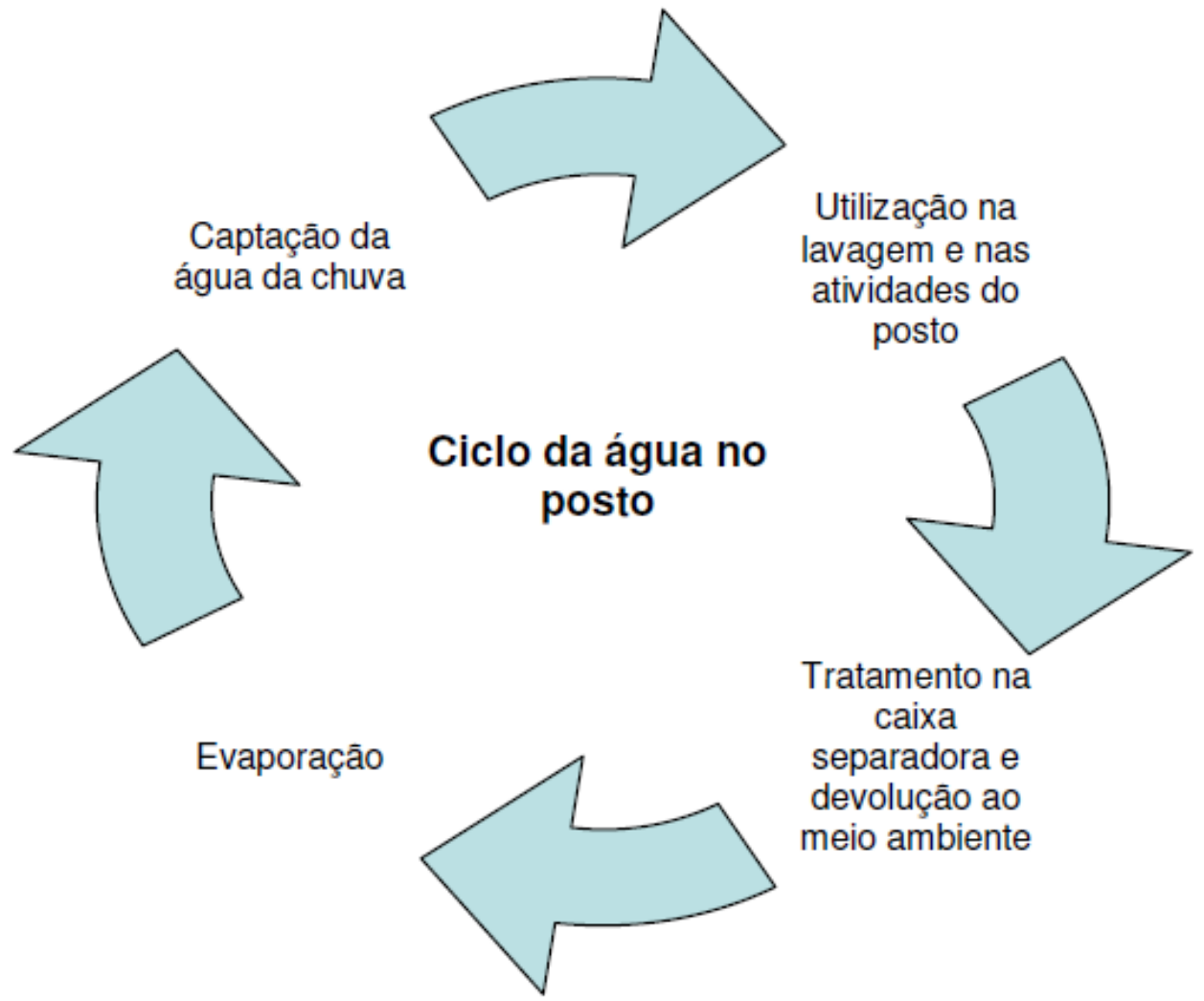

Fonte: Adaptado de Lorenzett et al. (2011)

Para a obtenção da Licença Prévia foram realizados os estudos de localização junto a FEPAM e a ANP; para obtenção da Licença de Instalação foram realizados os estudos de tecnologias e foram adotadas as bombas eletrônicas e os tanques ecológicos, bem como a estação de tratamento da água (caixa separadora) e para obtenção da Licença de Operação foram realizados os testes e ensaios nos equipamentos de forma a comprovar que estes estavam em conformidade com o sistema brasileiro de certificação, tendo o posto, portanto, passado pelas três fases do licenciamento ambiental, a Licença Prévia (LP), a Licença de Instalação (LI) e a Licença de Operação (LO).

\section{Considerações finais}

Atualmente, o mundo, vive uma fase onde o equilíbrio ambiental está em ascensão, os órgãos ambientais estão cada vez mais atuantes, e a legislação cada vez mais rigorosa. Com vistas a isso, no Brasil, o CONAMA lançou em 2000 a Resolução n 273, evidenciando a importância do controle e preservação ambiental por parte das empresas que atuam no segmento de comércio e distribuição de combustíveis. A referida norma objetiva estabelecer a padronização e o licenciamento ambiental das entidades que atuam nesse segmento.

No decorrer deste estudo foi observado que o posto de combustível estudado desenvolve as atividades de armazenamento de combustível, abastecimento e lavagem de veículos, troca de óleo, 
troca de filtros, lubrificação e loja de conveniência. Tais atividades mantêm relações diretas e intensas com o meio ambiente, através do contato com os compartimentos solo, água e ar, podendo causar impactos diretos e indiretos sobre a saúde humana, especialmente dos colaboradores que desenvolvem as atividades mencionadas.

Do trabalho de levantamento das medidas de gestão ambiental exigidas pela legislação vigente, como requisito para exercer a atividade de posto de combustível, foi constatado que o estabelecimento estudado vem adotando todas as medidas cabíveis, como: controle e detecção de vazamentos, tratamento dos efluentes líquidos e disposição final adequada dos resíduos gerados pela atividade, além de manter uma preocupação constante com a questão ambiental.

Através da pesquisa foi possível identificar, ainda, que os custos da gestão ambiental consistem na principal barreira e/ou dificuldade no momento da tomada de decisões para implantação de medidas de gestão ambiental. Entretanto, como a empresa estudada possuía recursos disponíveis para esse fim, foi possível implantar medidas de gestão ambiental que vão bem além das exigidas pela legislação vigente, como é o caso da utilização e tratamento da água da chuva, e da adoção de tanques subterrâneos ecológicos para o armazenamento dos combustíveis.

Para futuras investigações, fica a sugestão de trabalhar comparativamente, estudando um posto de combustível que esteja adequado às normas e um que não esteja adequado, para verificação quanto à restritividade da legislação, ou seja, até que ponto a legislação impede o funcionamento de postos com instalações irregulares.

\section{Abstract}

Because of environmental imbalance, the companies in the business of the gas stations, which are potentially polluting entities, come been trying to interact more harmoniously with the environment. In this context arose the need to identify the interaction of these institutions with the environment, which the environmental management measures are being adopted and which should be adopted by this business segment. Thus, this study sought to check the environmental management measures that should be adopted in accordance with existing environmental legislation. To develop the study was conducted a case study with the use of observation technique combined with the structured interview technique, along with a petrol station, located in Santa Maria - RS. The results revealed that the entity interacts with the environment when using water as input in the activities undertaken and by generation of waste such as: burned oil, used filters, toxic sludge, vapors of fuel, packs of lubricants and liquid effluents. It was noted also that these residues are all handled by the adoption of environmental management measures, suggesting that the company studied effectively contributes to environmental preservation.

Key-words: environmental management; environmental legislation; gas stations.

\section{Referências}

ADLMAIER, D.; SELLITTO, M. A. Embalagens retornáveis para transporte de bens manufaturados: um estudo de caso em logística reversa. Prod., São Paulo, v. 17, n. 2, ago 2007. Disponível em:

$<$ http://www.scielo.br/scielo.php?script=sci_arttext\&pid=S0103-65132007000200014\&lng=en\&nrm=iso $>$. Acesso em: 
27 Jun. 2011. doi: 10.1590/S0103-65132007000200014.

ANDRADE, M. M. de. Introdução a metodologia do trabalho científico: elaboração de trabalhos na graduação. 4. ed. São Paulo: Atlas, 1999.

BARATA, M. M. de L.; KLIGERMAN, D. C.; MINAYO-GOMEZ, C. A gestão ambiental no setor público: uma questão de relevância social e econômica. Ciênc. saúde coletiva, Rio de Janeiro, v. 12, n. 1, mar. 2007. Disponível em: $<$ http://www.scielo.br/scielo.php?script=sci_arttext\&pid=S1413-81232007000100019\&lng=en\&nrm=iso $>$. Acesso em: 29 Jun 2011. doi: 10.1590/S1413-81232007000100019.

BRAGA, B. et al. Introdução à engenharia ambiental. São Paulo: Prentice Hall, 2002.

CAVALCANTI, A. P. B. Implantação de programas de manejo e plano de gestão ambiental em pequenas comunidades. Soc. nat. (Online), Uberlândia, v. 22, n. 3, dez 2010. Disponível em:

$<$ http://www.scielo.br/scielo.php?script=sci_arttext\&pid=S1982-45132010000300010\&lng=en\&nrm=iso $>$. Acesso em: 20 maio 2011. doi: 10.1590/S1982-45132010000300010.

CONAMA. Resoluções: resolução n ${ }^{\circ} 273$ de 29 de novembro de 2000. [s.1.]: CONAMA, 2000. Disponível em: $<$ http://www.mma.gov.br/port/conama/res/res00/res27300.html>. Acesso em: 25 Set. 2010.

ESCRIVAO, G.; NAGANO, M. S.; ESCRIVAO FILHO, E. A gestão do conhecimento na educação ambiental. Perspect. ciênc. inf., Belo Horizonte, v. 16, n. 1, mar. 2011. Disponível em:

$<$ http://www.scielo.br/scielo.php?script=sci_arttext\&pid=S1413-99362011000100006\&lng=en\&nrm=iso $>$. Acesso em: 29 Jan. 2011. doi: 10.1590/S1413-99362011000100006.

FECOMBUSTÍVEIS. Meio Ambiente. Rio de Janeiro: Fecombustíveis, 2011. Disponível em: $<$ http://www.fecombustiveis.org.br/meio-ambiente.html>. Acesso em: 15 abr. 2011.

FREY, M. R.; WITTMANN, M. L. Gestão ambiental e desenvolvimento regional: uma análise da indústria fumageira. EURE (Santiago), Santiago, v. 32, n. 96, ago. 2006. Disponível em:

$<$ http://www.scielo.cl/scielo.php?script=sci_arttext\&pid=S0250-71612006000200006\&lng=es\&nrm=iso $>$. Acesso em: 30 jun. 2011. doi: $10.4067 / \mathrm{S} 0250-71612006000200006$.

JACOBI, P. Educação ambiental, cidadania e sustentabilidade. Cadernos de Pesquisa, São Paulo, n. 118, p.189-205, mar. 2003.

LAGARINHOS, C. A. F.; TENORIO, J. A. S. Tecnologias utilizadas para a reutilização, reciclagem e valorização energética de pneus no Brasil. Polímeros, São Carlos, v. 18, n. 2, Jun 2008. Disponível em:

$<\mathrm{http} / /$ www.scielo.br/scielo.php?script=sci_arttext\&pid=S0104-14282008000200007\&lng=en\&nrm=iso $>$. Acesso em: 28 Jun. 2011. doi: 10.1590/S0104-14282008000200007.

LEITE, P. R. Logística reversa: meio ambiente e competitividade. 2. Reimpressão. São Paulo, SP: Pearson Prentice Hall, 2006.

LORENZETT, D. B.; ROSSATO, M. V. A gestão de resíduos em postos de abastecimento de combustíveis. Revista Gestão Industrial, v. 6, n. 2, p. 110-125. Ponta Grossa, PR, 2010. Disponível em:

$<$ http://www.pg.utfpr.edu.br/depog/periodicos/index.php/revistagi/article/view/598/479>. Acesso em: 29 Jun. 2011.

LORENZETT, D. B. et al. Gestão de recursos hídricos em postos de combustíveis. Diálogos \& Ciência, v. 9, n. 26, p. 01-11. Salvador, Bahia, 2011. Disponível em:

$<$ http://dialogos.ftc.br/index.php?option=com_content\&task=view\&id=273\&Itemid=1>. Acesso em: 28 Jun. 2011.

MARCONI, M. de A.; LAKATOS, E. M. Fundamentos de metodologia científica. 6. ed. São Paulo: Atlas, 2005.

MARTINS, G. de A. Estudo de caso: uma estratégia de pesquisa. São Paulo: Atlas, 2006.

MASSOUD, J. A.; DAILY, B. F.; BISHOP, J. W. Perceptions of environmental management systems: An examination of the Mexican manufacturing sector. Industrial Management \& Data Systems, v. 111, n. 1, pp.5 - 19, 2011.

Disponível em: <doi10.1108/02635571111099703>. Acesso em: 29 jun. 2011.

RICHARDSON, R. J. Pesquisa social: métodos e técnicas. 3. ed. 9. Reimpressão. São Paulo: Atlas, 2008. 
RONNENBERG, Sh. K.; GRAHAM, M. E.; MAHMOODI. F. The important role of change management in environmental management system implementation. International Journal of Operations \& Production

Management, v. 31, n. 6, pp.631 - 647, 2011. Disponível em: <doi10.1108/01443571111131971>. Acesso em: 23

maio 2011.

SANTOS, R. J. Sh. dos. A gestão ambiental em posto revendedor de combustíveis como instrumento de prevenção de passivos ambientais. 2005. 217f. Dissertação (Mestrado em Sistemas de Gestão do Meio Ambiente) - Universidade

Federal Fluminense, Niterói, 2005.

TINOCO, J. E. P.; KRAEMER, M. E. P. Contabilidade e gestão ambiental. São Paulo: Atlas, 2004.

\section{Dados dos autores:}

Nome completo: Daniel Benitti Lorenzett

Filiação institucional: Universidade Federal de Santa Maria (UFSM)

Departamento: Programa de Pós-Graduação em Engenharia de Produção

Função ou cargo ocupado: Mestrando

Endereço: Av. Roraima, 1000, P. 07, S. 319, Camobi - Santa Maria/RS, CEP: 97105-900, Brasil.

Telefones para contato: (55) 32208619

e-mail:dlorenzett@gmail.com

Nome completo: Marivane Vestena Rossato

Filiação institucional: Universidade Federal de Santa Maria (UFSM)

Departamento: Curso de Ciências Contábeis

Função ou cargo ocupado: Professor Adjunto

Endereço: Rua Mal. Floriano Peixoto, 1184, $6^{\circ}$ andar, Centro - Santa Maria - RS.

Telefones para contato: (55) 32209260

e-mail:marivavest@gmail.com

Nome completo: Mauricio Neuhaus

Filiação institucional: Universidade Federal de Santa Maria (UFSM)

Departamento: Programa de Pós-Graduação em Engenharia Agrícola

Função ou cargo ocupado: Mestrando

Endereço: Av. Roraima, 1000, P. 44, $3^{\circ}$ andar, Camobi - Santa Maria/RS, CEP: 97105-900, Brasil.

Telefones para contato: (55) 32208158 
e-mail:mcneuhaust@gmail.com

Enviado em: 22/02/2011

Aprovado em: 01/08/2011 